\title{
Control of 3x7 matrix converter with PWM three intervals modulation
}

\author{
Mohamed Mounir Rezaoui $^{1 *}$, Noureddine Bessous $^{2}, \operatorname{Imad}_{\text {Merzouk }}{ }^{1}$ \\ ${ }^{1}$ LAADI, Faculty of Science and Technology, University of Djelfa 17000 DZ, ALGERIA \\ ${ }^{2}$ Faculty of Science and Technology, University of El Oued 39000 DZ, ALGERIA \\ mm_rezaoui@yahoo.fr
}

\begin{abstract}
Direct Power conversion from fixed AC voltage into variable AC voltage is gaining a significant attention, especially in case of multi-phases machines/generators; for such reason a new algorithm to control $3 \times 7$ matrix converter $(M C)$ is developed in this paper, wherein the main aim is to control multi-phases induction motor/generator connected to the electrical grid with a novel converter (except matrix converter), for that the PWM three intervals modulation strategy is modified from the control of $3 \times 3 \mathrm{MC}$ to $3 \times 7 \mathrm{MC}$; which is directly connected to the network through a three phase input in order to overcome the supplying problems, on the other side seven phases have been used as an output to benefit the advantages of the multi-phases machines. This paper intends in the first place to explain the $3 \times 3 \mathrm{MC}$, then to manipulate the control equation for the purpose of making it suitable for controlling the 3x7 MC effectively, thus a good performance can be clearly seen according to the quality of the output voltage/current under typical $R-L$ load, the shift between phases and the THD evaluation. The obtained simulation results which demonstrate the efficiency of the new control algorithm are presented and discussed.
\end{abstract}

Keywords: $3 \times 3$ Matrix converter, $3 \times 7$ Matrix converter, PWM three intervals, $R$-L load, THD. Received: 07/10/2019 - Accepted: 15/11/2019

\section{Nomenclature}

$\begin{array}{ll}\mathrm{U}_{\mathrm{R}}, \mathrm{U}_{\mathrm{S}}, \mathrm{U}_{\mathrm{T}} & \text { Input Voltages of matrix converter } \\ \mathrm{U}_{\mathrm{A}}, \mathrm{U}_{\mathrm{B}}, \ldots & \text { Matrix converter output voltages } \\ \mathrm{R}, \mathrm{L} & \text { Load parameters } \\ \mathrm{w}_{\mathrm{i}}, \mathrm{w}_{\mathrm{o}} & \text { Input/ Output Pulsation } \\ \mathrm{m}, \mathrm{r} & \text { Modulation index, modulation rate } \\ \mathrm{S}_{\mathrm{ij}} & \text { Switch } \\ \mathrm{I}_{\mathrm{i}}, \mathrm{i}_{\mathrm{o}} & \text { Input / Output Currents } \\ f_{i} / f_{o} & \text { Input / Output frequency } \\ \mathrm{m}_{i j} & \text { Relative conduction time during the Kth } \\ \mathrm{t} & \text { sequence } \\ \mathrm{U}_{\mathrm{d}}, \mathrm{U}^{+}, \mathrm{U}^{-} & \text {Time } \\ & \text { Intermediate virtual potential, Virtual } \\ & \text { positive potential and Virtual negative } \\ {\left[\mathrm{M}_{\mathrm{R}}(\mathrm{t})\right]} & \text { potential } \\ {\left[\mathrm{M}_{\mathrm{O}}(\mathrm{t})\right]} & \text { Rectifier Matrix function } \\ \mathrm{U}_{\mathrm{cmk}} & \text { Inverter Matrix function } \\ & \text { Modulation function }\end{array}$




\section{Introduction:}

In industrial applications the current absorbed by the machine is very high, this will demand a special calibration for the switches current/voltage, high cost and protection (means: winding in the motor and switches in the converter) [1-3]. One of many solutions to resolve this problem is to enlarge the number of output phases which will increase the number of the switches in the converter (more output phases means more switches which leads to a less current through the switches by keeping the same power) [3-5]. In order to achieve this target, the authors of this paper are interested in the multi-phases machines and converters. Moreover, these machines can reduce the amplitude and increase the frequency of torque ripple [610]. However, the matrix converter has several advantages compared to the conventional converter [7-8].

It is obvious that this it is an AC-AC converter without DC link connected to the input. On the other side the passive elements of the energy storage, which form the intermediate circuit (generally capacitors) between the AC-DC conversion stage and the inverter are eliminated. It is therefore possible to reduce considerably the volume and the cost of the conversion stage [9-18]. The symmetry structure of the matrix converter allows ensuring the energy recovery directly to the supply system [9] [19-20]. In previous work, researchers are working hard on the $3 \times 3$ matrix converter (used 9 switches), three-phase has been used in the input, and similarly for the output; in this paper the $3 \times 7$ matrix converter (used 21 switches) is taken for example with R-L load, supplied by a three-phase network to avoid the problem of the specific supply of the multi- phases machine[13-14], therefore the model of A. Schuster [10], is successfully modified, which will allow to write equations to facilitate the control of $(3 \times 7)$ matrix converter.

Current advances in power electronics and the development of computing processors can consider a finer control of these machines by using PWM techniques [1525].

The main objective of the study of this converter is to use a modern converter and benefit from the advantages of the multi-phases machines by modifying the same equations, so a new control algorithm is developed to ensure this conversion function. In this paper, the proposed control strategy is studied and analyzed with simulation results of the waveform quality of the output voltage/ current and their THD are also discussed.

\section{Modeling of the matrix converter}

The matrix converter is a static frequency and voltage converter, it allows outwardly obtaining a multi-phases voltage: Amplitude and frequency, from a power supply network multi-phase voltages [11-13]. This converter topology is characterized by a matrix of twenty-one switches ( $3 \times 7$ matrix); network three phases in the input are connected to seven phases to feed a load through a bidirectional power switches. One switch of the matrix converter can be modelled by two diodes and two transistors $[6,10]$.

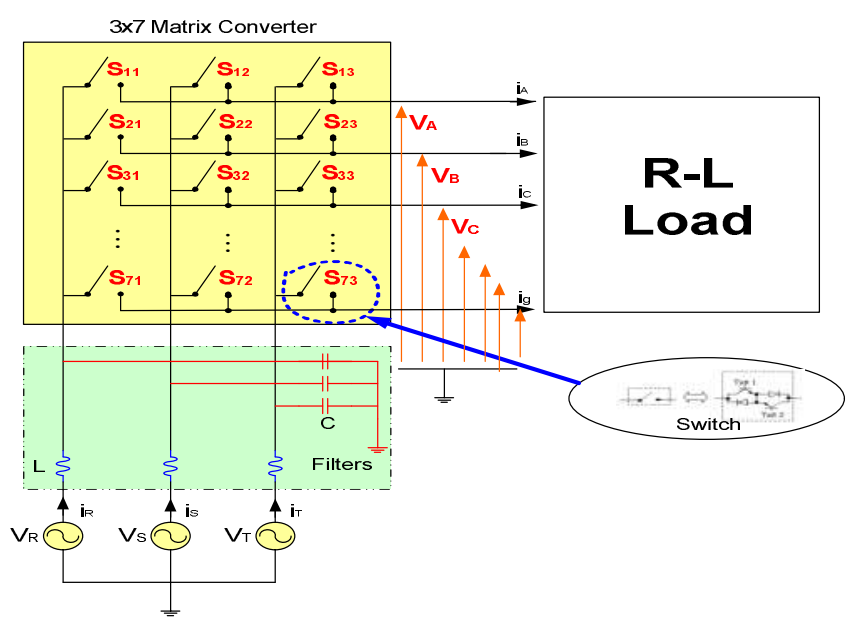

Figure 1. Schematic diagram $3 \times 7$ matrix converter

Since the converter is ideally coupled, the principle of causality leads to precise rules concerning the different states of the switches $[1,3]$ :

- Sources located on both sides of the group are necessarily different in their nature.

- Operating continuity requires energy to be retained, among the possible configurations of the operative part that are physically possible are: a non-zero voltage source can be short-circuited, a voltage source to zero can be set open circuit.

Finally, the number of the permissible configurations is reduced to $3^{7}$.

Table 1. Matrix converter configurations of one output phase

\begin{tabular}{cc}
\hline The configuration & $\begin{array}{c}\text { The value of output voltage } \\
\text { «Phase A» related to the input } \\
\text { voltages }\end{array}$ \\
\hline$E_{1}$ & $\mathrm{U}_{\mathrm{A}}=\mathrm{U}_{\mathrm{R}}$ \\
$\mathrm{E}_{2}$ & $\mathrm{U}_{\mathrm{A}}=\mathrm{U}_{\mathrm{S}}$ \\
$\mathrm{E}_{3}$ & $\mathrm{U}_{\mathrm{A}}=\mathrm{U}_{\mathrm{T}}$ \\
\hline
\end{tabular}

The cellular commutations present a symmetrical function and consequently a symmetrical control. The converter study intends to reduce the number of cellular commutations [10-13]; In this case three possible configurations appear, each of them is characterized by a quantity like it shown in Table 1.

\section{Control strategy of matrix converter}

The Principe of its control is based on the analogy of the indirect converter with an intermediate fictitious circuit (rectifier / inverter) $[6,10]$. So to talk about the 
complexity of the matrix converter control, the rectifier and the inverter parts are studied separately.

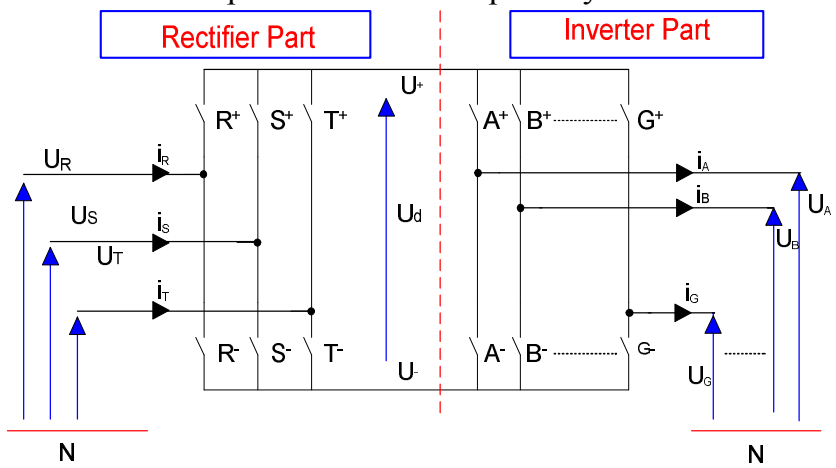

Figure 2. Model of the $3 \times 7$ matrix converter with middle fictitious circuit

The fact that at any given time, it must be at least one positive phase of the supply voltages and at least another negative one relative to neutral power, one can choose fictitious potentials $\mathrm{U}^{+}$and $\mathrm{U}^{-}$like:

$$
U_{d}=U^{+}-U^{-}
$$

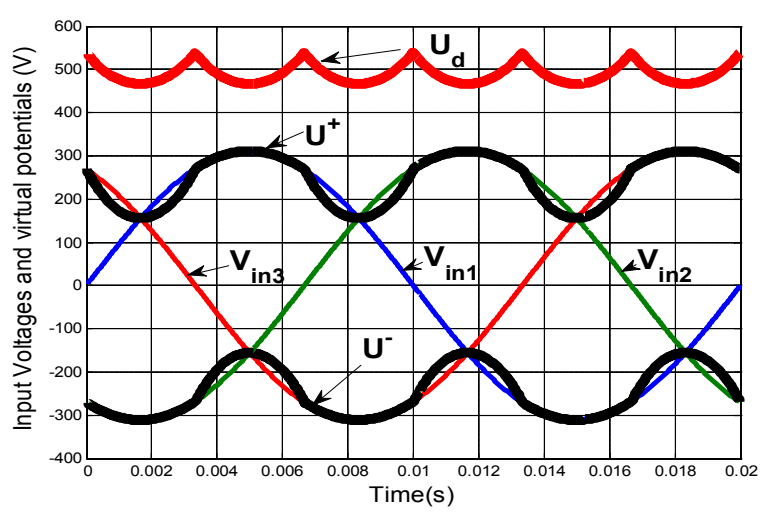

Figure 3. Curve of the input voltages and virtual potentials

In order to easily implement the rectifier, the matrix of the rectifier is defined to allow the connection between the input voltages and the intermediate part as follows [6, 10]:

$$
\tau=\frac{\cos \left(\Phi-\frac{\pi}{3}\right)}{\cos (\Phi)} \quad(0 \leq \tau \leq 1)
$$

The table of the function of modulation $\tau$ is elaborated by A. Schuster [10]:

$$
\left[\begin{array}{c}
U^{+} \\
U^{-}
\end{array}\right]=\left[\begin{array}{ccc}
R^{+} & S^{+} & T^{+} \\
R_{M_{R}(t)}^{R^{-}} & S^{-} & T^{-}
\end{array}\right]\left[\begin{array}{c}
V_{R} \\
V_{S} \\
V_{T}
\end{array}\right]
$$

$$
\left\{\begin{array}{l}
V_{R}=V_{m} \sin \left(\omega_{i} t\right) \\
V_{S}=V_{m} \sin \left(\omega_{i} t-2 \pi / 3\right) \\
V_{T}=V_{m} \sin \left(\omega_{i} t-4 \pi / 3\right)
\end{array}\right.
$$

Considering the symmetry founded in the recovery period, six intervals will appear as shown in Figure 3.

The functions $\mathrm{u}_{\mathrm{cmk}}$ of modulations will be introduced to be able to take continuous values between 0 and 1 to define the matrix modulation $\left[\mathrm{M}_{0}\right]$. This allows to create a link between the middle potential and the output voltages of the matrix converter, as follows:

$$
\left[\begin{array}{l}
V_{A} \\
V_{B} \\
V_{C} \\
V_{D} \\
V_{E} \\
V_{f} \\
V_{g}
\end{array}\right]=\left[\begin{array}{ll}
U_{c m 1} & 1-U_{c m 1} \\
U_{c m 2} & 1-U_{c m 2} \\
U_{c m 3} & 1-U_{c m 3} \\
U_{c m 4} & 1-U_{c m 4} \\
U_{c m 5} & 1-U_{c m 5} \\
U_{c m 6} & 1-U_{c m 6} \\
\underbrace{U_{c m}}_{c m 7} & 1-U_{c m 7}
\end{array}\right]\left[\begin{array}{l}
U^{+} \\
U^{-}
\end{array}\right]
$$

The equation (6) is obtained from the combination of the two equations (3) and (5):

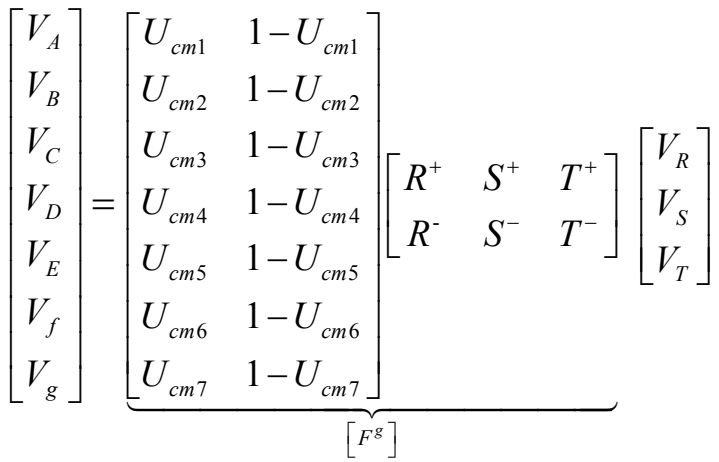

It finally comes to characterize the matrix $\left[F^{g}\right]$ which allows to define the complete algorithm for the frequency conversion such as:

$$
\left[\begin{array}{c}
V_{A} \\
V_{B} \\
V_{C} \\
V_{D} \\
V_{E} \\
V_{f} \\
V_{g}
\end{array}\right]=\left[\begin{array}{ccc}
F_{R A}^{g} & F_{S A}^{g} & F_{T A}^{g} \\
F_{R B}^{g} & F_{S B}^{g} & F_{T B}^{g} \\
F_{R C}^{g} & F_{S C}^{g} & F_{T C}^{g} \\
F_{R D}^{g} & F_{S D}^{g} & F_{T D}^{g} \\
F_{R E}^{g} & F_{S E}^{g} & F_{T E}^{g} \\
F_{R F}^{g} & F_{S F}^{g} & F_{T F}^{g} \\
F_{R G}^{g} & F_{S G}^{g} & F_{T G}^{g}
\end{array}\right]\left[\begin{array}{c}
V_{R} \\
V_{S} \\
V_{T}
\end{array}\right]
$$

The output reference voltage phases are defined as follows: 


$$
\left\{\begin{array}{l}
V_{A}=V_{m} \sin \left(\omega_{o} t\right) \\
V_{B}=V_{m} \sin \left(\omega_{o} t-2 \pi / 7\right) \\
V_{C}=V_{m} \sin \left(\omega_{o} t-4 \pi / 7\right) \\
V_{D}=V_{m} \sin \left(\omega_{o} t-6 \pi / 7\right) \\
V_{E}=V_{m} \sin \left(\omega_{o} t-8 \pi / 7\right) \\
V_{F}=V_{m} \sin \left(\omega_{o} t-10 \pi / 7\right) \\
V_{G}=V_{m} \sin \left(\omega_{o} t-12 \pi / 7\right)
\end{array}\right.
$$

With: $\omega_{o}=2 \pi f_{o}$

Determining the functions of waves (standard reference functions) consists to modulate the fictitious middle voltage given above:

(9)

$$
U_{c m k}=r \cos (\Phi) \sin \left(\omega_{o} t-2(k-1) \frac{\pi}{7}\right)+\frac{1}{2}
$$

$$
\mathrm{k}=1,2, \ldots, 7 \text {. }
$$

The PWM is a well-established technique for the multi-pulse converters. For that, the control of matrix converter in each output phase must be switched at each input phase during a specified range of the pulse period; therefore, the pulse period must be divided into three intervals (Number of input phases). For such reason, a technique similar to the one used in the conventional PWM modulators has been adopted [9]; the saw tooth reference signal will be compared to a control signal, a binary signal by phase will be generated according to the comparison, for the purpose of indicating the state of the power switch.

The carrier equation is defined as follows:

$$
U_{p}=\frac{t}{T} \quad 0<t<T_{p}
$$

The output binary signals $\mathrm{Xi}$ of PWM modulator is defined as follow [10]:

$$
X_{i}= \begin{cases}1 & \tau_{x i}>U_{p} \\ 0 & \text { if } n o t\end{cases}
$$

By taking into account the previous equations, the reference signals $\tau_{\mathrm{X}}$ are defined as:

$\left\{\begin{array}{c}\tau_{\mathrm{x} 1 \mathrm{k}}=R^{+} U_{c m k}+R^{-}\left(1-U_{c m k}\right) \\ \tau_{\mathrm{x} 2 \mathrm{k}}=S^{+} U_{c m k}+S^{-}\left(1-U_{c m k}\right)\end{array}\right.$

\section{Simulations and Results}

To have an overview about the behaviours of the presented algorithm, which has been tested by a simulation with $R-L$ load ( $R=20 \Omega, L=10 m H)$, the input voltages of the matrix converter is considered as a typical three-phase system which is characterized by a magnitude of $220 \mathrm{~V}$ and $50 \mathrm{~Hz}$ as a frequency, the switching frequency is chosen to be $2500 \mathrm{~Hz}$ with a modulation index $r=0.8$. The output voltages and currents obtained by the application of the modified PWM three intervals algorithm are presented in Figure 4 and Figure 5 respectively, the output voltages follow perfectly the reference, whereas in Figure.5 the output currents are shown, it is clearly noticed that the resulting output current drawing a nearly sinusoidal waveform.

The shift between voltage and the current (5x I) are showed in Figure. 6 and Figure. 7.

Whereas in Figure. 8 the input currents of $3 \times 7$ matrix converter are presented.

Figure 9 Output Voltage compared to the Output Current on the other side the harmonic spectrum of the output voltage, output current and the input current are represented in Figure 9, Figure 10 and Figure 11 respectively.

In Table .2, a summary of same results including THD and the fundamental values of the output voltage and input/output currents. It is obvious that the using of this algorithm ensures the maximum magnitude with a less THD compared with $3 \times 3$ matrix converter [6]; or $3 \times 5$ matrix converter [13]; on the other hand, the obtained output current is better and acceptable THD results from point of view of the sine waveform quality. The output current resulting from the adaptation of the proposed algorithm presents more important ripple which is characterized by THD $=15.87 \%$.

Table 2. Values of the fundamentals and their THD

\begin{tabular}{lll}
\hline Values & THD & fundamental \\
\hline Output voltage & $59.74 \%$ & $290.00 \mathrm{~V}$ \\
Output current & $15.87 \%$ & $14.32 \mathrm{~A}$ \\
Input current & $52.61 \%$ & $31.39 \mathrm{~A}$ \\
\hline
\end{tabular}
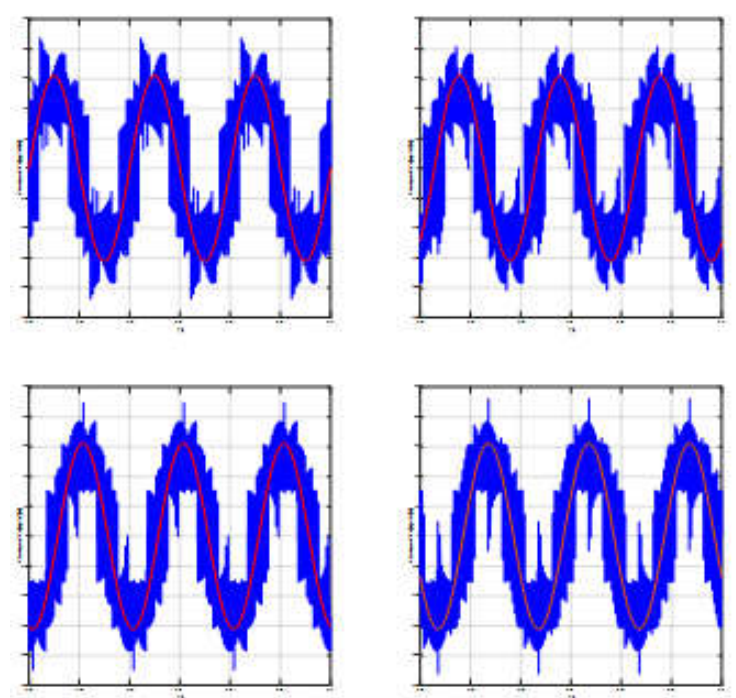

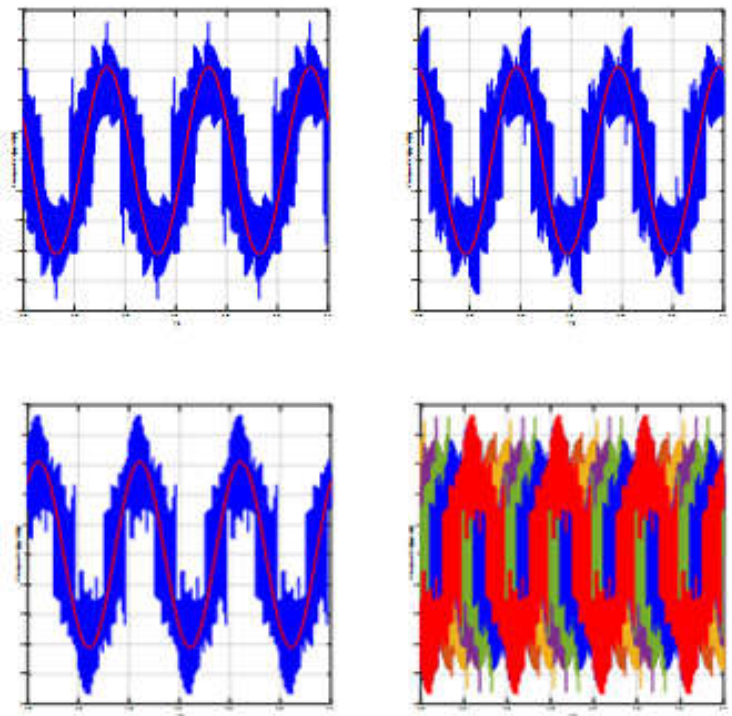

Figure 4. Output voltages of $3 \times 7$ matrix converter
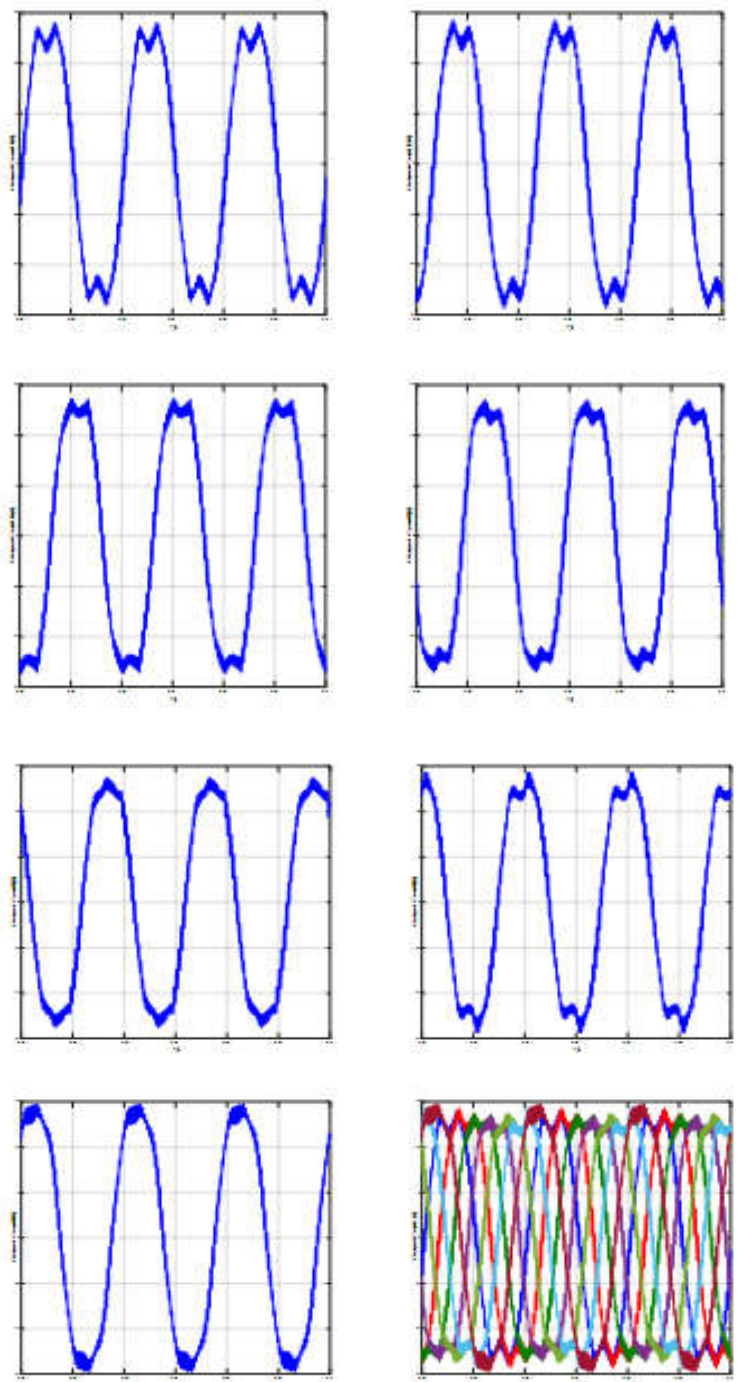

Figure 5. Output currents of $3 \times 7$ matrix converter

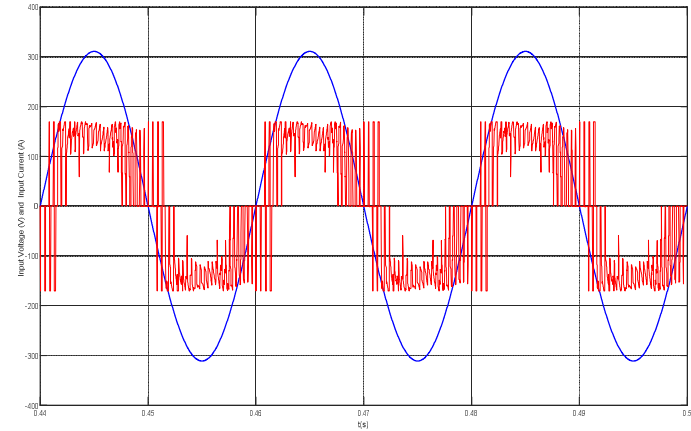

Figure 6. Input Voltage compared to the Input Current

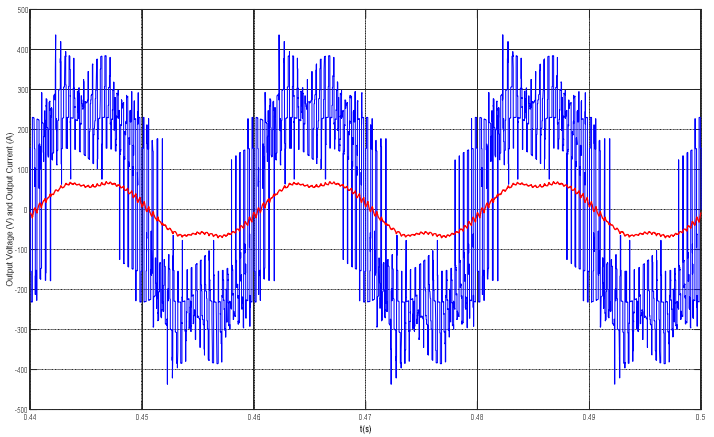

Figure 7. Output Voltage compared to the Output Current
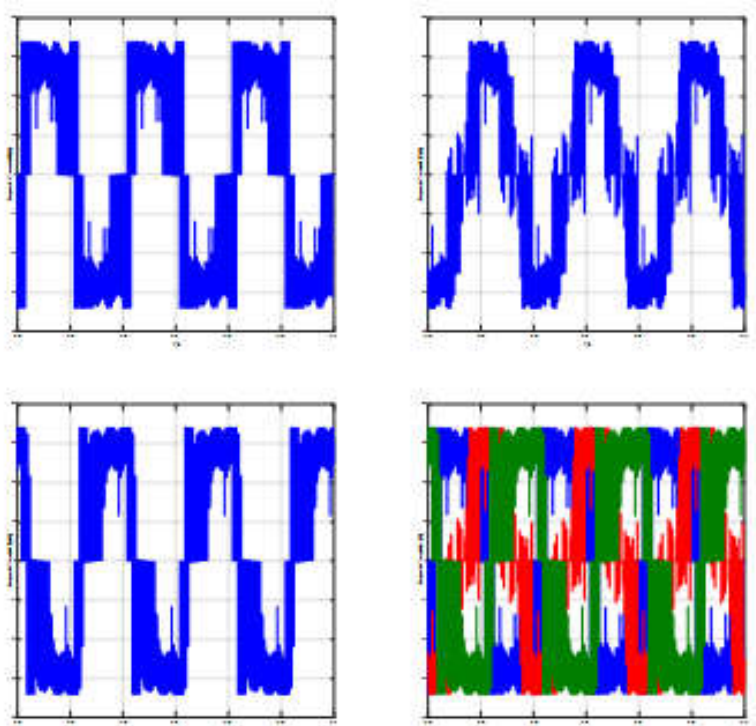

Figure 8. Output currents of $3 \times 7$ matrix converter 


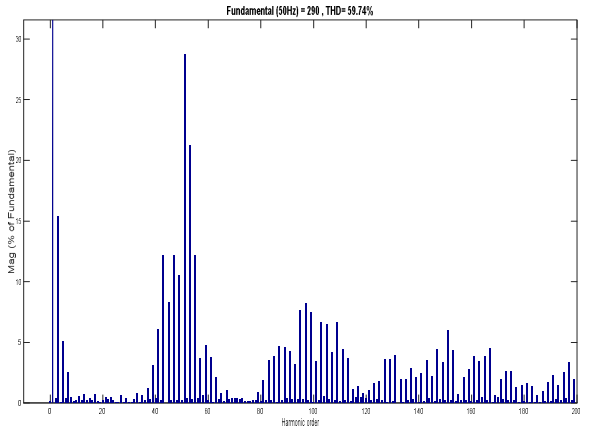

Figure 9. The harmonic spectra of output voltage

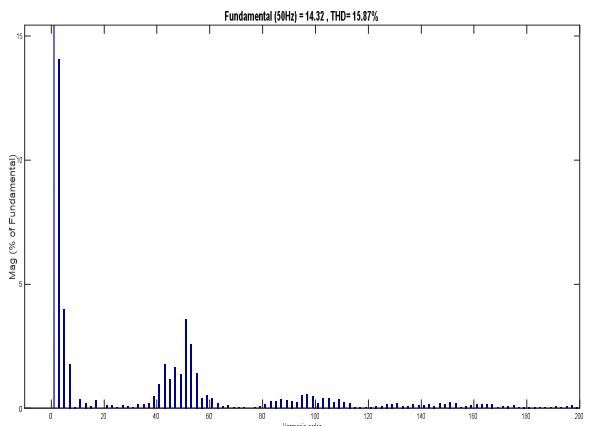

Figure 10. The harmonic spectra of output current

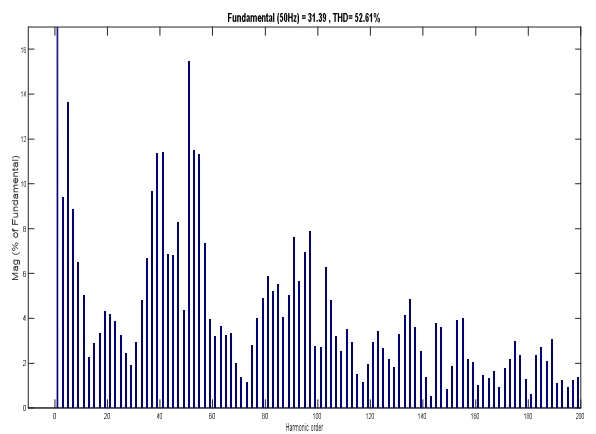

Figure 11. The harmonic spectra of input current

\section{Conclusion}

In the present work, a modified PWM three intervals algorithm is applied to control a $3 \times 7$ matrix converter. Simulation experiments of the proposed approach are achieved and the results which clarifying its behaviour are presented and discussed; after the examination of this method, it was found that the output voltages and input/output currents have an acceptable waveform, and thus allows obtaining better results. On the other side, the output voltages of $3 \times 7$ matrix converter are following perfectly their reference, which has been given a value of $290 \mathrm{~V}$ with a THD of $59.74 \%$. The shift between phases is equal to $\pi / 7 \mathrm{rad}$ or $51.43^{\circ}$, which represents the shift phase between the output voltages and the output currents. Finally, the proposed algorithm gives better results and ensuring more flexibility and suitability when used for the control of the $3 \times 7$ matrix converter.

\section{References}

[1] K. Bedoud, A. Rhif, T. Bahi, H. Merabet. "Study of a double fed induction generator using matrix converter: Case of wind energy conversion system". International Journal of Hydrogen Energy, Vol. 43, no 25, 2018, pp. 11432-11441.

[2] M. Ali, A. Iqbal, M. Rizwan Khan, M. Ayyub, M.A. Anees. "Generalized Theory and Analysis of Scalar Modulation Techniques for a mxn Matrix Converter". IEEE Transactions on Power Electronics, Vol. 32, No 6, 2017, pp. 4864-4877.

[3] M. Ali, A. Iqbal, M. Rizwan Khan. "4: AC-AC Converters". Science Direct. 4th edition Power Electronics Handbook, 2018, pp. 417-456.

[4] N.H. Saad, A.A. El-Sattar, M.E. Marei. "Improved bacterial foraging optimization for grid connected wind energy conversion system based PMSG with matrix converter". Ain Shams Engineering Journal, Vol. 9 , No 4, 2018, pp. 92183-2193.

[5] P. Gambôa, J.F. Silva, S.F. Pinto, E. Margato. "Input-Output Linearization and PI controllers for AC-AC matrix converter based Dynamic Voltage Restorers with Flywheel Energy Storage: a comparison". Electric Power Systems Research, Vol. 169, 2019, pp. 214-228.

[6] M.M. Rezaoui, L. Nezli, M.O. Mahmoudi. "High Performances of Five-Phase Induction Machine Feeding by a [3×5] Matrix Converter". Journal of electrical engineering (JEE), Vol. 65, No 2, 2014, pp. 83-89.

[7] T.D. Nguyen, H.H. Lee. "Carrier-based PWM Technique for Three-to-Five Phase Indirect Matrix Converters". IECON'11 - 37th Annual Conference on IEEE Transactions on Industrial Electronics Society, 2011, pp. 3662-3667.

[8] A. Djahbar, B. Mazafu, M. Latroch. "Control strategy of three-phase matrix converter fed induction motor drive system". IEEE International Workshop on Intelligent Signal Processing, 2005, pp. 104-109.

[9] J. Rodriguez, M. Rivera, J.W. Kolar, P.W. Wheeler. "A Review of Control and Modulation Methods for Matrix Converters". IEEE Transactions on Industrial Electronics, 59(1), 2012, pp. 58-70.

[10] A. Schuster. "A drive system with a digitally controlled matrix converter feeding an AC induction machine". IEEE Conference on Power Electronics and Variable Speed Drives, Nottingham, UK, 1996, pp. 23-25.

[11] O. Abdel-Rahim, H. Abu-Rub, A. Iqbal, A. Kouzou. "Five-to-three phase direct matrix converter with model predictive control", Power Engineering, Energy and Electrical Drives (POWERENG) ", 2013 Fourth International Conference on, Istanbul, Turkey, 13-17 May 2013.

[12] S. Moin Ahmed, H. Abu-Rub, , Z. Salam, A. Iqbal, "Dual matrix converters based seven-phase open-end winding drive". IEEE, 23rd International 
Symposium on Industrial Electronics (ISIE), Istanbul, Turkey, 1-4 June 2014.

[13] M.M. Rezaoui, L. Nezli, M.O. Mahmoudi, A. Kouzou, H. Abu Rub. "A Modified PWM three intervals Control for a Matrix converter in Real Time". Archives of Control Sciences (ACS), Vol. 24 , No 1, 2014, 85-98.

[14] O. Abdel-Rahima, H. Abu-Ruba, A. Kouzou. "Nineto-Three Phase Direct Matrix Converter with Model Predictive Control for Wind Generation System". Energy Procedia, (vol. 42), 2013, pp. 173-182.

[15] T.D. Nguyen, L. Hong-Hee. "Development of a Three-to-Five-Phase Indirect Matrix Converter with Carrier-Based PWM Based on Space-Vector Modulation Analysis". IEEE Transactions on Industrial Electronics", Vol. 63, No 1, 2016, pp. 13 24.

[16] C. Klumpner, F. Blaabjerg, I. Boldea, P. Nielsen. "New modulation method for matrix converters. IEEE Transactions on Industry Applications", Vol. 42, No 3, 2006, pp. 797-806. 